\title{
De accountant en de voorziening schaden
}

\section{Inleiding}

Dit artikel beoogt te verkennen wat de openbare accountant moet doen teneinde, in het kader van de controle van de jaarrekening van een schadeverzekeringsmaatschappij, zekerheid te verkrijgen ten aanzien van de aanvaardbaarheid en de volledigheid van de post voorziening schaden. Daaronder wordt verstaan de voorziening voor schadeclaims die ten laste van het afgelopen boekjaar dienen te komen, doch waarvan de definitieve afwikkeling eerst in een volgende verslagperiode plaatsvindt.

Het is waarschijnlijk dat de huidige, onjuiste, benaming 'schadereserve' in de nabije toekomst officieel zal worden vervangen. In de gedistribueerde concept verslagstaten in het raam van de komende Wet Toezicht Schadeverzekeringsbedrijf wordt, binnen de rubriek technische voorzieningen, de aanduiding 'voorziening schaden' gebruikt. In dit artikel zal waar mogelijk ook voor andere grootheden de nieuwe terminologie worden gebezigd, omdat is aan te nemen dat ook in publikatieverslagen en andere documenten geleidelijk de nieuwe benamingen zullen verschijnen.

De voorziening schaden is de belangrijkste passiefpost op de balans van een schadeverzekeringsmaatschappij. Dat belang is in de loop van de jaren toegenomen, getuige de volgende tabel:

Passiva binnenlandse

$1967 \quad 1974 \quad 1981$

verzekeringsmaatschappijen

Aansprakelijk vermogen

Voorziening premies

Voorziening schaden

Voorziening fondsen

Crediteuren

Overige passiva

$\begin{array}{rrr}33 \% & 31 \% & 28 \% \\ 21 & 22 & 23 \\ 22 & 31 & 34 \\ 5 & 4 & 2 \\ 11 & 8 & 9 \\ \frac{8}{100 \%} & \frac{4}{100 \%} & \frac{4}{100 \%}\end{array}$

Bron: Verslagen van de Verzekeringskamer.

Commerciële betekenis van de voorziening schaden

Voor de schadeverzekeraar is de voorziening schaden van grote betekenis voor het toetsen van de prijsstelling van de verzekeringsprodukten en het nemen van andere beleidsbeslissingen. Uit het verloop van de voorziening schaden en de gedane betalingen kan de verzekeringsmaatschappij immers 
afleiden of de veronderstellingen gemaakt ten tijde van het berekenen van de benodigde risicopremie valide zijn geweest. Hoewel de activiteiten van de accountant zich primair richten op de getrouwheid van de financiële verslaglegging, kunnen zijn bevindingen terzake van de omvang van de door de verzekeraar opgemaakte voorziening schaden een wezenlijke bijdrage betekenen aan het bedrijfsbeleid.

\section{Schattingsprobleem}

Het kernprobleem van de betrouwbaarheid van de voorziening schaden voor onderneming, accountant en toezichthoudende autoriteiten - ligt in het vermogen van mensen om zo juist mogelijke schattingen te doen bij snel wijzigende omstandigheden. Die mogelijkheden variëren per branche en worden voorts bepaald door de fase van het schadebehandelingsproces waarin de schatting wordt gegeven. De omstandigheid dat gegevens omtrent de betaalde schaden en het verloop van de voorziening schaden bij alle verzekeringsmaatschappijen van enige betekenis reeds geruime tijd in computerbestanden zijn opgeslagen, maakt het mogelijk mathematische technieken toe te passen voor de berekening van de voorziening. Naar verwachting zal zich de komende jaren op dit punt een verdere ontwikkeling voltrekken. De accountant zal, in het kader van de attestfunctie, zich in deze problematiek moeten verdiepen.

\section{De samenstelling van de voorziening schaden}

De meeste auteurs maken de samenstelling van de voorziening schaden tot een eenvoudige tweedeling: schaden gemeld en schaden niet gemeld. Voor het verbeteren van de kwaliteit van de schattingen is met name nodig de categorie nog niet gemelde schaden nader te onderscheiden en enige andere elementen van de voorziening schaden te introduceren. Dan ontstaat de volgende indeling:

\section{Bekende maar nog niet afgewikkelde schaden}

Betreft de in behandeling zijnde schaden per balansdatum ten aanzien waarvan nog een actie wordt verwacht.

2 Voorgevallen, maar nog niet gemelde schaden, in de praktijk aangeduid als IBNR (incurred but not reported)

De IBNR schaden kunnen als volgt onderverdeeld worden:

$a$. schadegevallen die door de verzekerden nog niet aan de verzekeringsmaatschappij zijn gemeld of door hen nog niet als schaden zijn ervaren;

$b$. schaden die door de verzekeringsnemer of een derde aan de verzekeringsmaatschappij zijn gemeld, maar die om welke reden dan ook nog niet in de schade-administratie zijn opgenomen ('pijplijn schaden');

c. afgewikkelde schaden die in de toekomst wellicht heropend moeten worden. Dit betreft in het bijzonder intermitterende en recidiverende gevallen in de medische branches. 


\section{Te maken schadeafwikkelingskosten}

Betreft de kosten van behandeling van de op balansdatum nog niet afgewikkelde schaden. Bedoeld worden zowel de door de verzekeringsmaatschappij intern uit te geven bedragen (met name personeelskosten) als de aan derden (advocaten, taxateurs, e.d.) te betalen vergoedingen. De kosten van derden worden in het algemeen in aanmerking genomen per individueel schadegeval en de interne kosten worden en bloc aan de branches toegerekend.

In de U.S.A. en Canada is dit onderdeel van de technische voorzieningen reeds jaren een geaccepteerd verschijnsel. In Nederland heeft tot dusverre ogenschijnlijk slechts een deel van de verzekeringsmaatschappijen een voorziening voor interne schadeafwikkelingskosten gevormd.

4 Vereveningsvoorziening voor branches met een sterk wisselend schadeverloop

Is een begrip dat in de nieuwe w.T.S.-verslagstaten is opgenomen, in navolging van toepassing in West-Duitsland.

\section{Ontvangsten uit hoofde van regres en revindicatie}

De verplichting tot uitkeren op grond van de polisvoorwaarden kan gepaard gaan met het recht van regres op de veroorzaker van de schade. Verwachte opbrengsten uit hoofde van regres of uit de verkoop van teruggevonden of herstelde goederen, worden veelal als een aftrekpost per individueel schadegeval geregistreerd.

\section{Zee-, transport-en luchtvaartverzekering}

Volledigheidshalve wordt gewezen op het bijzondere karakter van de technische voorziening bij de hoofdbranche zee-, transport- en luchtvaartverzekering, welke aldaar voorziening fondsen wordt genoemd. Deze voorziening kan worden beschouwd als een combinatie van de voorziening premies en de voorziening schaden. Het is als het ware een fonds waarin de risicopremies worden afgezonderd ter dekking van de schade-uitkeringen. Elke verzekeringsmaatschappij hanteert een eigen methodiek bij de bepaling van de opbouw van het fonds. Veelal wordt het resultaat van een tekenjaar eerst na een aantal jaren verantwoord.

\section{De berekening van de voorziening schaden}

Niet zo lang geleden was het gebruikelijk om de voorziening schaden te bepalen als de optelsom van de per schadegeval gedane schattingen van schadebedrag en externe schadeafwikkelingskosten, verhoogd met een bedrag voor IBNR. Volledigheidshalve zij opgemerkt dat het steeds gaat om de voorziening schaden eigen rekening. Het voor rekening van herverzekeraars komende gedeelte van de te verwachten schade-uitkeringen is op de voorziening in mindering gebracht.

Bij grote aantallen gelijksoortige schaden, b.v. casco schaden van motorrijtuigen, ging men geleidelijk over tot toepassing van zogenaamde gemiddelde waarden. Dit werd in de hand gewerkt door de voortschrijdende automati- 
sering. Daardoor werd het mogelijk het aan de gemiddelde schade toe te kennen bedrag uit de afgewikkelde schadegevallen af te leiden. Niet alleen gelijksoortigheid maar ook snelle afwikkeling vormt een voorwaarde voor toepassing van gemiddelden.

Voor de bepaling van de omvang van de IBNR schaden worden allerlei vuistregels en rekentechnieken gehanteerd. De eenvoudigste is het toepassen van een percentuele opslag op de voorziening schaden met betrekking tot in behandeling zijnde schaden, variërend per branche. Ofschoon in de loop der jaren bepaalde nameldingspatronen zichtbaar zijn geworden, leren met name de ervaringen in de U.S.A. dat zeer talrijke nameldingen kunnen worden gedaan die de vaststelling van de IBNR voorziening tot een hachelijke zaak maken, zeker indien het betrekkelijk nieuwe verzekeringsvormen betreft.

Het is gebruik geworden om in de resultatenrekening van een schadeverzekeringsmaatschappij de in het verslagjaar gemaakte kosten van de schadebehandelingssector als element van de schadelast te beschouwen. De verhouding tussen de schadebehandelingskosten en de betaalde schaden of de schadelast wordt vaak gebruikt om het bedrag te bepalen dat naar verwachting nodig is om de per balansdatum lopende schaden af te wikkelen, nl. door het bedoelde verhoudingscijfer toe te passen op de voorziening schaden. Het aldus berekende bedrag wordt als een opslag aan de voorziening toegevoegd.

Te verwachten is dat de genoemde traditionele methoden voor het bepalen van de voorziening schaden zullen worden aangevuld door statistische analyses en projecties ter toetsing en correctie van de door de operationele afdelingen van de verzekeringsmaatschappij vastgestelde voorziening. Daarop wordt in paragraaf VIII nader ingegaan.

\section{De schadebehandeling}

Behoudens de zeer kleine bedrijven beschikken verzekeringsmaatschappijen over computerinstallaties van imponerende capaciteit. Uit diverse onderzoeken is gebleken dat het verzekeringswezen de hoogste graad van automatisering heeft bereikt van alle bedrijfstakken. Er mag daarom worden gesteld dat de detailgegevens van de voorziening schaden van de belangrijkste branches in computerbestanden zijn opgenomen. De controlerend accountant zal bij de beoordeling van de voorziening schaden derhalve altijd met automatiseringstoepassingen in aanraking komen.

Tot voor enige jaren waren de schadebehandelingssystemen gebaseerd op groepsgewijze verwerking van gegevens. Meer en meer worden die systemen omgebouwd naar postgewijze verwerking van invoergegevens met behulp van beeldschermen, al dan niet op basis van gedistribueerde intelligentie. De computerproduktie van de benodigde formulieren en het bijwerken van de hoofdbestanden geschiedt veelal batchgewijs aan het einde van de werkdag.

De schadebehandeling vindt over het algemeen plaats door een aparte 
schadeafdeling, soms onderscheiden naar branche. Terwille van een goede verdeling van de verwachte werkzaamheden binnen een schadeafdeling, worden schaden volgens vooraf vastgestelde criteria aan bepaalde groepen of individuele schadebehandelaars toegewezen. Voorbeelden daarvan zijn: regio, letterserie, tussenpersoon, collectiviteit of aard van de schade. De accountant ziet er op toe dat de bedoelde werkverdeling formeel wordt vastgelegd. Bij de beoordeling van een schadebetaling of een voorziening schaden moet hij toetsen of de schade door de juiste groep of persoon is behandeld.

Naarmate de doorlooptijd van een schade langer is of het met een schade gemoeide bedrag hoger is, neemt het aantal bij een schadegeval betrokken functionarissen toe. Bij de opzet van de schadebehandeling moet voorgeschreven worden dat, door het plaatsen van handtekening of paraaf plus datering, zichtbaar wordt gemaakt welke functionaris aan een schade heeft gwerkt. Bij het testen van de werking van de administratieve organisatie zal de accountant pogen vast te stellen of de door het bedrijf voorschreven procedures metterdaad zijn gevolgd. Dat wil voor de voorziening schaden in dit verband zeggen: vastgesteld door een bevoegde functionaris en, indien nodig, met de voorgeschreven frequentie beoordeeld door andere functionarissen.

\section{Fasen in de schadebehandeling}

Uitgaande van postgewijze verwerking van de schadegegevens verloopt het schadebehandelingsproces in hoofdlijnen als volgt:

\section{Fase 1: Het melden van een schade}

Aan de hand van de schriftelijke of telefonische melding van de verzekerde worden de schadevoorvalgegevens in het computersysteem ingebracht. Soms is deze handeling opgedragen aan een aparte sector binnen de schadeafdeling. In ieder geval wordt de primaire registratie van de schademelding door een andere functionaris verricht dan de schadebehandelaar. De ingetoetste schadegegevens worden door de programmatuur geconfronteerd met de polisgegevens (dekkingscontrole) en de schadehistorie van de polis. De programmatuur initieert voor bepaalde branches een voorlopige aanpassing van toekomstige premiebepalende factoren (b.v. nieuwe bonus/malus trede bij autoverzekeringen) of verzorgt de berichtgeving aan de polisafdeling teneinde de premievoorwaarden bij te stellen of de verzekering te doen beëindigen. Het computersysteem eist opgave van een initiële waarde van de voorziening schaden per schadegeval. De schademelding wordt aan de tussenpersoon bevestigd, waarbij ontbrekende gegevens worden opgevraagd. Het computersysteem houdt agenderingsdata vast. Eventueel wordt een schade-expert benoemd. De op de melding betrekking hebbende stukken worden in een schadedossier opgeborgen of op microfilm opgenomen.

\section{Fase 2: Het muteren van de voorziening schaden}

Zodra nadere gegevens beschikbaar komen over een schadegeval wordt de voorziening schaden opnieuw bezien en desgewenst gemuteerd. De mutatiedatum wordt in het schadebestand vastgehouden, evenals - als het goed 
is - de voorgaande waarde van de voorziening schaden. Ook het verstrijken van een bepaalde periode kan aanleiding zijn om de voorziening schaden te muteren, b.v. indien de schade aanvankelijk een gemiddelde waarde werd toegekend en de afwikkeling langer duurt dan werd voorzien.

\section{Fase 3: Het initiëren van een schadebetaling}

Dit geschiedt veelal op grond van een ontvangen expertiserapport of een verantwoording van de verzekerde. De documenten worden gecontroleerd door de schadebehandelaar aan de hand van de in het schadedossier en/of schadebestand opgenomen gegevens. De voorziening schaden wordt van een nieuwe waarde voorzien.

Dit deel van het schadebehandelingsproces is het meest kwetsbare, omdat geldmiddelen het bedrijf verlaten hetzij direct door een rechtstreekse overschrijving naar de verzekerde of diens tegenpartij hetzij door creditering in rekening-courant van de rekening van de tussenpersoon. Alvorens de schadebetaling wordt geëffectueerd zullen altijd een of meer andere, daartoe geautoriseerde, functionarissen de betaling beoordelen. Daarbij zal ook aandacht gegeven worden aan de nieuwe waarde van de voorziening schaden. (Ook andere maatregelen van interne controle, die in het kader van dit artikel verder onbesproken blijven, zullen toepassing vinden.)

\section{Fase 4: Het afleggen van een schade}

Wanneer uit het schadevoorval geen verdere vorderingen of verplichtingen te verwachten zijn, wordt al dan niet bij de laatste betaling of een regresontvangst, het schaderecord in een passieve status gebracht. De voorziening schaden wordt per definitie door de schadebehandelaar of de programmatuur op nul gesteld.

\section{Bemoeienis van de accountant met de systeemopzet}

De doeltreffendheid en de doelmatigheid van het controleprogramma van de accountant met betrekking tot het schadebehandelingsproces worden in belangrijke mate bepaald door zijn inbreng tijdens de ontwikkelingsfase van de geautomatiseerde systemen. Naast de controlemogelijkheden die uit functiescheiding voortkomen, zal er in het bijzonder aandacht zijn voor de volledigheid en de juistheid van de invoergegevens en voor de rappel-en rapportagefunctie van de programmatuur.

Met betrekking tot de invoer van gegevens is er alles aan gelegen om de bestanden uitsluitend met 'schone' gegevens te vullen. Dat betekent een veelomvattende validiteits- en plausibiliteitscontrole, gebruik makend van gegevens in andere computerbestanden met name het polisbestand. Enige voorbeelden zijn

- programmatische verificatie van een schademelding met de van kracht zijnde polisgegevens op de evenementsdatum;

- non-acceptatie door het computersysteem ingeval van ontbreken van een schade-oorzaakcode, een bedrag of een codering aangevende de schade-omvang, etc.; 
- weigering door de programmatuur om een schadegeval af te sluiten indien er nog regres wordt verwacht.

Behalve door de computerprogrammatuur wordt de inbreng van de schadegegevens gecontroleerd door het inschakelen van andere functionarissen dan degene die de primaire vastlegging verrichtte bij:

$a$. de visuele controle van beeldschermgegevens; of

$b$. de 'blinde' dubbele vastlegging van bepaalde brongegevens;

c. de extra autorisatie benodigd bij 'boven limiet' schaden;

$d$. de vergelijking van computeruitvoergegevens met brondocumenten.

De invoer van gegevens kent nog een ander belangrijk facet. Dat is het waarborgen dat de beeldschermeenheden alleen door daartoe geautoriseerde functionarissen kunnen worden gebruikt. De procedures die de toegang tot de computerbestanden en het gebruik van de systeemfuncties regelen, zullen vaak van toepassing zijn voor het gehele bedrijf. De accountant zal zich intensief met dit onderwerp bezighouden en er op toezien dat a. zo mogelijk een keuze wordt gemaakt voor een systeem van zogenaamde dynamische passwordtoekenning, waarbij per systeemgebruiker wordt geregistreerd welke wijzigingen in de passwords worden aangebracht;

$b$. opzet en wijzigingen in de competentietabel nauwlettend worden geverifieerd met de formele interne organisatie van de verzekeringsmaatschappij;

c. pogingen om ongeautoriseerd toegang te verkrijgen tot het computersysteem door de programmatuur worden gedetecteerd;

d. bij elke transactie wordt vastgehouden welke beeldschermeenheid en welke functionaris daarbij betrokken is geweest en dat daarover dagelijks een verslaglegging wordt vervaardigd;

e. van sensitieve toepassingen b.v. schadebetalingen, ook achteraf nogmaals de bevoegdheid van de betrokken functionaris wordt onderzocht. Het gaat de accountant overigens niet uitsluitend om een optimale screening van de invoergegevens en een afdoende protectie tegen ongeautoriseerd beeldschermgebruik. Evenzeer van betekenis is het vormgeven aan een zodanige administratieve organisatie dat duurzame aanvaarding van de gestelde regels door het personeel te verwachten is. De psychologische aspecten van de systeembouw worden vaak onvoldoende onderkend. Dat leidt dan tot op papier indrukwekkende systemen die door hun ingewikkeldheid de suggestie opwekken dat aan eisen van interne controle in hoge mate is voldaan. Het effect in de praktijk kan echter zijn dat de systeemgebruikers de betekenis er van niet begrijpen of zich simpelweg niet aan de procedures houden. Het is als met beveiligingsmechanismen op houtbewerkingsmachines: hoe ingewikkelder toe te passen hoe minder ze worden gebruikt.

De rappel- en rapportagefunctie houdt verband met de noodzaak de schadegegevens voortdurend actueel te houden. Er moet rekening mee worden gehouden dat de voorziening schaden voor het personeel in de schadeafdelingen niet bijster interessant is. Het is voor hen meer een gegeven dat voor de financiële functie van de onderneming van belang is. Een prikkel om de voorziening schaden voortdurend bij te werken ontbreekt. Het perio- 
diek toetsen door de programmatuur van de actualiteit van de voorziening schaden is daarom noodzakelijk. Voorbeelden daarvan zijn:

- het signaleren wanneer een schadegeval enige tijd niet gemuteerd is;

- het dwingen om een aanvankelijk van een 'gemiddeld bedrag' voorziene schade na verloop van een bepaalde tijd (tussen 30 en 180 dagen zegt

T. M. Peterson, 1981) een specifiek bedrag toe te kennen.

Hoe de accountant zijn inbreng tijdens de systeemontwikkeling organiseert hangt voornamelijk af van het feit of de betrokken verzekeringsmaatschappij beschikt over een verbijzonderd interne controle-orgaan met voldoende automatiseringskennis. Het minste wat gedaan moet worden is het tijdig formuleren van eisen van interne controle terzake van de te bouwen systemen en het tijdens de fasen van systeemontwikkeling vaststellen dat de automatiseringsfunctionarissen zich er aan houden.

\section{Beoordeling van de voorziening schaden}

$\mathrm{Bij}$ het beoordelen van voorzieningen gaat het de accountant om de aanvaardbaarheid en de volledigheid er van. De aanvaardbaarheid van de voorziening schaden is niet dan met een ruime marge te benaderen vanwege $a$. het schattingselement in de nog niet afgewikkelde schaden;

$b$. de onbekendheid met het aantal en de omvang van de IBNR schaden. Het vaststellen van de volledigheid van de aan de verzekeringsmaatschappij gemelde schaden is niet zo'n probleem, zoals zal blijken. Anders ligt het met de volledigheid van de IBNR schaden. Die is op de balansdatum slechts bij wijze van schatting te bepalen.

\section{Eigen actie van de controlerend accountant}

Evenals bij de participatie tijdens de fasen van de systeemontwikkeling, zal de mate van activiteit van de controlerend accountant bij het testen van de werking van de administratieve organisatie en de beoordeling van de systeemuitkomsten mede bepaald worden door het al dan niet aanwezig zijn van een verbijzonderd intern controle-orgaan. De meeste schadeverzekeraars van enige omvang beschikken over een dergelijke interne controle afdeling, vaak geleid door een registeraccountant. De controlerend accountant beoordeelt alle rapportages van de interne controle afdeling met betrekking tot de naleving van procedures bij de schadebehandeling, de bevindingen bij de nacontrole van individuele schadegevallen en de ontwikkeling van elk van de elementen van de voorziening schaden. Tenzij de eigen cijferbeoordeling van de ontwikkeling van de voorziening schaden daartoe aanleiding geeft, controleert de accountant slechts in uitzonderingsgevallen individuele schadegevallen.

\section{Beoordeling van de bekende schaden}

Voor wat betreft de in behandeling zijnde schaden levert de computer periodiek een bestandsoverzicht van de voorziening schaden, gerubriceerd naar verschillende gezichtspunten. De eerste vraag zal zijn: 'is het overzicht volledig'. Dat kan vastgesteld worden door vanuit de voorgaande stand aan de hand van de produktieverslagen van de computerverwerkingen de nieuwe 
stand te controleren, niet alleen naar aantal maar ook naar status van de schadegevallen. Ook afgemelde schaden zullen nl. veelal geruime tijd in het schadebestand achterblijven met het oog op eventuele heropening, ter wille van presentatie aan de schadebehandelaar bij toekomstige schademeldingen onder dezelfde polis en omdat bij sommige branches de premiestelling gekoppeld is aan de frequentie van zogenaamde schuldschaden. Nuttig algemeen controlemiddel is het volgen van de schadefrequentie in de loop van de jaren, dat is de verhouding tussen het aantal schademeldingen en het aantal verzekerde objecten.

Een aanvullende controle op de voorziening schaden vindt plaats door de periodieke beoordeling door leidinggevende functionarissen van schadegevallen waarvan het geschatte schadebedrag of de schadelast een per branche bepaalde grens overschrijdt. Voorts wordt de voorziening schaden betrokken in de steekproefsgewijze controle van schadegevallen, waarbij de correspondentiedossiers worden gelicht. Op grond daarvan en mede naar aanleiding van speciale procedurecontroles, ter plaatse uitgevoerd door het verbijzonderde controle-orgaan, kan tevens getest worden of de administratieve organisatie volgens de uitgevaardigde instructies metterdaad heeft gewerkt. De controle of de voorziening als zodanig per schadegeval correct is vastgesteld, beperkt zich tot de verificatie of degene die de schatting heeft opgemaakt daartoe bevoegd is, alsmede of de door deskundigen opgegeven bedragen juist zijn overgenomen. Onder de deskundigen bevinden zich schade-experts, taxateurs, medici en accountants; de laatsten ingeval van onderzoeken naar de omvang van bedrijfsschade en fraude. Voorzover de controlerend accountant zelf kennis neemt van rapporten van deskundigen, bijv. in het kader van de steekproefsgewijze controle van schadegevallen, beperkt zijn controle zich tot kritische beoordeling. Gezond verstand speelt overigens op meer punten bij de toetsing van de voorziening schaden een rol.

\section{Beoordeling van gemiddelde waarden}

Indien voor bepaalde categorieën schaden gemiddelden worden gebruikt is het zaak periodiek vast te stellen of de gehanteerde gemiddelde waarden nog actueel zijn. Dat kan geschieden door de schaden die in het verleden als gemiddeld waren aangemerkt, te volgen tot aan de afmelding en aldus een voortschrijdend bedrag te bepalen. Ook is van belang te controleren of lopende schaden na verloop van tijd inderdaad van een specifiek bedrag worden voorzien.

\section{Beoordeling van de IBNR voorziening}

Over de IBNR voorziening zal de accountant per branche willen oordelen mede op grond van computeroverzichten die tonen hoe de in voorgaande jaren gestelde IBNR voorziening zich heeft ontwikkeld. Voorts zal de accountant alert zijn op omstandigheden die de IBNR voorziening beïnvloeden, zoals wijziging in het aantal verzekerde objecten en/of het premie-inkomen, verschuiving in afsluitdata en vertraging in administratieve verwerking door welke oorzaak dan ook. 
Evenals bij de bekende schaden zal ook aan externe factoren aandacht worden gegeven, zoals het verwachte inflatiepercentage, de hoogte van de wettelijke rente, mogelijke wijzigingen in wetgeving en rechtspraak alsmede de weersomstandigheden in de periode voorafgaande aan de jaarultimo.

\section{Beoordeling van interne schadeafwikkelingskosten}

Wanneer de verzekeringsmaatschappij een voorziening heeft gevormd voor toekomstige interne schadeafwikkelingskosten zal de accountant de jaarlijkse mutatie daarin moeten beoordelen. Dat houdt in dat de berekeningswijze moet worden vergeleken met die van voorgaande jaren en de uitkomsten moeten worden nagerekend.

\section{Uitloopstatistieken}

Enig houvast of de verzekeringsmaatschappij over het algemeen redelijke schattingen van de voorziening schaden opstelt, vindt de accountant in uitloopstatistieken. Daarin wordt per evenementsjaar tot uitdrukking gebracht of de voorziening schaden per balansdatum toereikend is geweest of niet. In het jaarverslag van de Verzekeringskamer wordt van de verzekeringsmaatschappijen in de N.V.-vorm een samenvatting gegeven. Daaruit blijkt dat de vrijgekomen bedragen de nadelige verschillen verre overtreffen. In 1981 bleek het voordelige verschil voor in totaal 93 vennootschappen ruim $f 333$ miljoen te bedragen. Nochtans was er een niet gering aantal ondernemingen dat in een of meer branches een tekort op de voorziening schaden van voorgaande jaren moest melden (totaal $f 80$ miljoen).

De uitloopstatistieken zeggen uiteraard niets over de voorziening schaden met betrekking tot de in het verslagjaar gemelde schaden alsmede de IBNR schaden. Met andere woorden: ook al was de voorziening schaden in het verleden toereikend dan nog kan de voorziening per balansdatum onvoldoende zijn. De accountant is daarom continu attent op indicaties dat het voorheen gevolgde beleid bij de vaststelling van de voorziening schaden mogelijk is gewijzigd.

\section{Indirect bedrijf en volmachttekening}

Naast het hoofdbedrijf, de directe tekening, dragen verzekeringsmaatschappijen via inkomende herverzekering, ook wel indirect bedrijf genoemd, een deel van het risico op posten die door een collega verzekeraar zijn gesloten. Van oudsher wordt van herverzekeringscontracten slechts zeer summiere informatie over premie en schade uitgewisseld en dan veelal nog vertraagd. Dat voegt een moeilijkheid toe aan de bepaling van de voorziening schaden. Liggend op hetzelfde vlak, maar soms van aanzienlijk groter betekenis in termen van premie-inkomen en schadelast, zijn de verzekeringen die tot stand zijn gekomen via een door de verzekeringsmaatschappij aangestelde gevolmachtigd agent. De verzekeringsmaatschappij houdt van door gevolmachtigden gesloten verzekeringen veelal geen schaduwadministratie bij, maar volstaat met een controle van de door de gevolmachtigde periodiek ingezonden premie- en schadeopgaven, waarvan de opgave van de voorziening schaden deel uitmaakt. 


\section{Cijferbeoordeling}

In de literatuur is weinig te vinden over de mogelijkheden om de voorziening schaden met behulp van cijferbeoordeling te toetsen. Die absentie is merkwaardig, omdat het in de bedrijfstak niet ongebruikelijk is om de 'outgo' per branche in de vorm van een schadepercentage en een kostenpercentage weer te geven. Drs. C. Griffioen schrijft er in de bundel 'Accoord' (1975) het volgende over: 'Schadepercentages kunnen zich met name in de shortrun zeer vreemd gedragen. Doch ook bij cijferbeoordelingen over langere perioden moet aan dit controlemiddel geen overwegende betekenis worden toegekend. Slechts indien en voorzover de financiële administratie voorziet in een separate verantwoording van de massaschades en de topschades kan cijferbeoordeling zinvol zijn.'

Het feit dat de grotere schadebedrijven de schadeadministratie geautomatiseerd hebben en tevens over het algemeen per branche voldoende aantallen homogene schadegevallen hebben, houdt in dat interne cijferbeoordeling zonder al te veel moeite kan worden uitgevoerd. De accountant kan daarvan gebruik maken.

Wat door de controlerend accountant waarschijnlijk nog onvoldoende wordt gedaan is bedrijfsvergelijking, terwijl toch aan jaarverslagen en vrij verkrijgbare w.O.S.-verslagstaten gedetailleerde informatie is te ontlenen. Bedrijfsvergelijking kan een belangrijk controlemiddel worden.

Snelle conclusies op grond van bedrijfsvergelijking zijn overigens te ontraden. Er kunnen nl. goede gronden zijn voor ongelijk niveau of afwijkend verloop van de voorziening schaden bijv. de samenstelling van de verzekeringsportefeuille, het gekozen premieniveau, de ouderdom van de portefeuille, uitgevoerde saneringsacties en het groeitempo.

\section{Nieuwe ontwikkelingen en de accountant}

In de U.S.A. - goed voor $50 \%$ van de wereldmarkt in schadeverzekeringen (Nederland 2\%) - is de laatste jaren een ontwikkeling opgetreden die ook voor ons land wel eens van belang zou kunnen zijn. Gedoeld wordt op de toenemende betekenis van mathematische technieken om de voorziening schaden te bepalen. De behoefte om de voorziening schaden op andere dan de conventionele wijze te benaderen, is voortgekomen uit de volgende factoren:

a. de groei van het aantal aansprakelijkheidsclaims en de toename van de daarmede gemoeide bedragen;

$b$. de langere termijn waarbinnen IBNR schaden worden gemeld, o.a. vanwege het zich openbaren van beroepsziekten (asbestverwerking in 1940 - schadeclaim in 1980);

c. de veranderende instelling van de rechterlijke macht (toekennen smartegeld).

\section{Mathematische technieken}

De ontwikkelingen staan nog in de kinderschoenen vanwege:

$a$. het feit dat de voor de analyses benodigde gegevens nog niet gedurende lange tijd beschikbaar staan; 
$b$. het ontbreken van zekerheid over de betrouwbaarheid van de uitkomsten van de berekeningen en de algemene toepasbaarheid ervan.

Drie toepassingen zijn te onderscheiden:

a. projecties van de voorziening schaden voor de op balansdatum nog niet afgewikkelde schaden door toepassing van extrapolatie-modellen op basis van hetzij betaalde schade hetzij schadelast;

$b$. idem, maar dan met een separate extrapolatie van de aantallen en de bedragen, eveneens steunend op schadeafwikkelingspatronen zoals die zich in het verleden hebben voorgedaan;

c. projecties van de vermoedelijke omvang van de IBNR voorziening, gebaseerd op in het verleden geconstateerde naijlingspatronen per branche.

\section{Accountant en actuaris}

Als de ontwikkelingen in de U.S.A. ook in Nederland zichtbaar worden, zullen meer dan voorheen mathematisch geschoolden, d.w.z. actuarissen en econometristen, hun werkterrein vinden in de schadeverzekering. Daarvoor zijn ook in Nederland zelf enige aanwijzingen te vinden:

a. de inschatting van actuarissen zelf (artikel Verbraak 1982);

$b$. de meer geprononceerde rol van de actuaris in het kader van de w.T.S.verslaggeving (ondertekening door actuaris van bepaalde staten);

c. de bijdrage van actuarissen op het gebied van de premiestelling (introductie bonus/malus methode personenautoverzekeringen, 1982).

De vraag is wat de houding van de accountant moet zijn. Wat betreft de voorziening schaden lopen de belangen van actuaris en accountant parallel omdat beiden streven naar verbetering van de methoden tot vaststelling van de voorziening. Samenwerking is dus op zijn plaats om met de automatiseringsstaf van de verzekeringsmaatschappij de gegevensverzamelingen op te bouwen en passende programmatuur te ontwikkelen. Een aanleiding voor de accountant om eigen programma's te ontwikkelen om de schadedatabank te gebruiken, lijkt vooralsnog te ontbreken. Voorwaarde is dan wel, dat hij niet terzijde blijft staan maar actief deelneemt teneinde de te zijner tijd aan hem voorgelegde analyses op waarde te kunnen beoordelen. 


\section{Literatuur}

Boeken

T. M. Peterson, Loss Reserving property/casualty insurance, 1981

- K. A. Tucker, D. P. van Mieghem, Federal taxation of insurance companies, hoofdstuk $10-13,1982$

- Verslag van de Verzekeringskamer ingevolge de wet op het schadeverzekeringsbedrijf over 1982

\section{Artikelen}

- H. Gerritsen, De nieuwe verslagstaten levensverzekering en schadeverzekering, Het Verzekeringsarchief, 1982

- H. Gerritsen, De actuaris, de accountant en de jaarrekening, Het verzekeringsarchief, 1977

- Drs. C. Griffioen, Beoogde zekerheden in de procesorganisatie van schadeverzekeringsmaatschappijen, bundel Accoord, 1975

- B. M. Landa, Schadeverzekering, Encyclopedie van de bedrijfseconomie, 1970

- Ch. Modijefsky, De accountantscontrole bij verzekeringsbedrijven, Handboek Accountancy, 1977

- R. J. Smit, De evolutie van de bedrijfseconomische grondslagen voor de jaarrekening van de nederlandse verzekeringsmaatschappijen, De balans opgemaakt, Jubileum uitgave 100 jaar Moret \& Limperg, 1983

- Statement of financial accounting standards no 60 , Accounting and reporting by insurance companies, 1982

- Statement of principles regarding property and casualty loss and loss adjustment expense liabilities, Casualty Actuarial Society, 1978

- Statement on auditing standards no. 11, Using the work of a specialist, Aicpa, 1976

- H. L. F. Verbraak, Het vak van actuaris, Financieel \& Administratief Management, 17 juni 1982 